\title{
PROEVEN MET STOFFEN, DIE AANTREKKEND, AFSTOOTEND OF SCHADELIJK WERKEN OP DE RUPSEN VAN PRODENIA LITURA Fb.
}

DOOR

\author{
Dr. L. P. DE BUSSY.
}

Onder de insecten, die van groote beteekenis zijn voor de Delische tabakscultuur, treden een tweetal Lepidoptera, Heliothis (Chloridea) obsoleta F. en Prodenia litura Fb. sterk op den voorgrond. De rupsen van deze beide Noctuiden toch, die zich bij voorkeur met tabak voeden en daarbij kleinere of grootere gaten in de bladeren knagen, zijn somtijds uiterst algemeen en kunnen dan een zeer groote economische schade veroorzaken; te duidelijker zal dat den oningewijde worden, wanneer hij bedenkt, dat de Deli-tabak uitsluitend als dekblad voor sigaren gebruikt wordt, en dat dekblad uit den aard der zaak volkomen onbeschadigd moet zijn. Zelfs betrekkelijk weinig aangevreten tabaksbladeren zijn daarom belangrijk minder waard dan geheel gave bladeren.

In sommige jaren kan de door deze rupsen teweeggebrachte schade wel op enkele millioenen guldens geraamd worden; het is dus niet te verwonderen, dat de Delische tabaksplanters van het begin hunner cultuur af aan den strijd daartegen aangebonden hebben en dat het biologisch onderzoek ervan en het beramen van maatregelen ertegen steeds een paar hoofdpunten van het werkprogramma van het Deli Proefstation, de wetenschappelijke instelling van de Delische tabakscultuur, hebben gevormd.

Bestreed men de plaag aanvankelijk alleen door de rupsen te laten zoeken en dooden, in 1906 en 1907 verwierven de door het Deli Proefstation ingevoerde insecticiden Schweinfurter Groen en loodarsenaat zich snel burgerrecht, en sinds dien hebben deze zich steeds gehandhaafd en zijn zij voor den tabaksplanter onmisbaar gebleven.

Evenwel, afdoende kunnen deze middelen nog niet genoemd worden; zij dooden de rupsen wel, wanneer die een hoeveelheid ervan binnengekregen hebben, maar het bleek, dat de rupsen de aanwezigheid van deze stoffen .op het tabaksblad, ook al zijn de toegediende hoeveelheden weinig $(1 \%$ in cassave-meel of fijn stof van Schweinfurter Groell, enkele procenten in dezelfde verdunningsmiddelen van loodarsenaat) spoedig ontdekken, van de ermede bedekte bladgedeelten niet meer eten en zich naar de onbehandelde plekken begeven; in de praktijk is het nl. niet mogelijk alle bladeren van alle tabaksplanten volkomen gelijkmatig met het giftige mengsel te bepoederen.

Er zijn nog andere nadeelen aan het gebruik der genoemde insecticiden verbonden (soms de inwerking op het bladweefsel, wanneer de stof niet op de juiste wijze gefabriceerd is; het gehalte aan arsenicum van beide stoffen; de kleur van het loodarsenaat, dat men in sterker concentratie dan het Schweinfurter Groen moet gebruiken), en het is daarom niet te verwonderen, dat ernstig gezocht is en wordt zoowel naar geschikte vervangers als naar stoffen, die men zou kunnen toevoegen om de afstootende werking op de rupsen van het Schweinfurter Groen en het loodarsenaat op te heffen, zonder de doodelijke te verminderen. Tijdens mijn werkzaamheid aan het Deli Proefstation heb ik een groot aantal proeven in die richting genomen, waarvan hieronder eenige vermeld worden.

De werkmethode was aldus: was de te onderzoeken stof van drogen aard, dan werd zij òf 
onverdund gebruikt òf in een zeker percentage zoo fijn en zoo gelijkmatig mogelijk verdeeld in cassavemeel; met dat homogene mengsel werden daarna reepen versch, uitwendig niet vochtig tabaksblad zeer gelijkmatig bestrooid; bleek het niet mogelijk het materiaal fijn te verdeelen, dan werden in warm en koud water aftreksels van verschillende sterkte ervan gemaakt en daarmede reepen tabaksblad besproeid, die men liet opdrogen, vóór de proef werd ingezet.

In de meeste gevallen werden als proefdieren rupsen van Prodenia litura Fb. gebruikt; van deze kan men zonder bezwaar een aantal, ook als zij gebrek aan smakelijk voedsel hebben, in dezelfde ruimte bijeenhouden, daar zij niet als de rupsen van Heliothis tot kannibalisme overgaan.

De bestrooide of besproeide reepen tabaksblad werden met een aantal goed gezonde rupsen onder groote glazen klokken gebracht; en het gedrag der proefdieren nagegaan.

De eerste serie proeven toont zeer duidelijk de afkeer der rupsen van met Schweinfurter Groen (S. G.) behandeld voedsel.

Proef 1 . 20 volwassen rupsen bij reepen tabaksblad, waarvan:

$\mathrm{n}^{0} .1$ en 4 onbehandeld,

$\mathrm{n}^{0} .2$ en 5 met S. G. $1 \%$ in cassave-meel,

$\mathrm{n}^{0}$. 3 en 6 met S. G. $1 \%$ in cassave-meel, en bovendien $10 \%$ saccharose in meel.

$\mathrm{Na} 24$ uur waren $\mathrm{n}^{0}$. 1 en 4 geheel opgegeten en was van de andere 4 slechts heel weinig geknabbeld.

Proef 2. 20 kleine en halfwassen rupsen bij reepen tabaksblad, met:

$\mathrm{n}^{0}$. 1. S. G. $1 \%$ in cassave-meel,

$\mathrm{n}^{0}$. 2. S. G. $1 \%$ in saccharose,

$\mathrm{n}^{0}$. 3. niets,

$n^{0}$. 4. S. G., $1 \%$ in een mengsel van cassave-meel met $10 \%$ saccharose.

Alleen van de reepen $\mathrm{n}^{0} .3$ was na 24 uur flink gegeten.

Proef 3. 5 bijna volwassen rupsen bij reepen tabaksblad, met

$\mathrm{n}^{0}$. 1. fijne droge saccharose,

$\mathrm{n}^{0}$. 2. S. G. $1 \%$ in saccharose.

$\mathrm{Na}$ een etmaal is $n^{0} .1$ opgegeten, $n^{0} .2$ bijna niet aangeroerd.

Zonder uitzondering wijzen de uitslagen van alle deze proeven er op, dat de rupsen zeer wel bespeuren, of op een tabaksblad S. G. al dan niet aanwezig is, en dat zij bij vrije keuze verreweg de voorkeur geven aan de niet daarmede behandelde bladeren.

Ik mag niet nalaten hier ter plaatse reeds erop te wijzen, dat, wanneer geen nieuw voedsel gegeven werd, de rupsen in hun honger ten slotte ook de met S. G. behandelde tabak opaten, en dan korten tijd daarna te gronde gingen. In de vrije natuur zal een rups echter trachten een onbehandeld stuk blad te vinden.

$\sim$ Een andere serie proeven had ten doel na te gaan, of stoffen gevonden konden worden, die met bijzondere graagte gegeten werden, en zoo ja, of dat dan in die mate het geval was, dat daardoor, wanneer mengsels gebruikt werden, de afkeer voor S. G. overwonnen werd:

Proef 4. 20 halfwassen rupsen bij tabak met:
1. niets
6. melampyriet, $100 \%$
2. glucose, $100 \%$
7. saccharose, $100 \%$
3. lactose, $100 \%$
8. tannine, $10 \%$
4. maltose, $100 \%$
9. niets
5. manniet, $100 \%$
10. S. G. $1 \%$ in meel met saccharose.

De tabak met niets, $n^{0} .1$, die met maltose $\left(n^{0} .4\right)$ en met saccharose $\left(n^{0} .7\right)$ bepoederd verdwenen het snelst, minder mel die met glucose $\left(n^{0} .2\right)$, lactose $\left(n^{0} .3\right)$, manniet $\left(n^{0} .5\right)$ en melampyriet $\left(\mathrm{n}^{0}\right.$. 6), terwijl de bevochtiging met $10 \%$ tannine vrij sterk afstootend werkte, en aan $\mathrm{n}^{0}$. 10 , S. G. $1 \%$ in meel + saccharose nauwelijks geknabbeld werd.

Van een voorkeur voor een der onderzochte stoffen boven de controle-tabak is niets gebleken; 
ook de smaak van het S. G. is, gelijk trouwens de hiervóór vermelde proeven reeds aantoonden, niet noemenswaardig door die van de ermede vermengde saccharose overdekt.

Vervolgens werd nagegaan, of saccharine eenige uitwerking op de rupsen had.

Proef 5. 20 bijna volwassen rupsen bij tabak met:

n.. 1 en 4 niets,

$\mathrm{n}^{0} .2$ en 5 , bevochtigd met een oplossing van 5 tabletten saccharine in $50 \mathrm{cM}^{3}$ water,

$n^{0} .3$ en $6, \quad, \quad, \quad, 10 \%$ saccharose.

Alles werd zonder eenige voorkeur of tegenzin opgegeten.

Evenmin als saccharose kon saccharine de aanwezigheid van S. G. in een mengsel voor de rupsen verborgen houden, gelijk deze proef bewijst:

Proef 6. 6 halfwassen Prodenia's bij tabak met:

$n^{0}$. 1. S. G., $1 \%$ in meel.

no. 2. S. G., $1 \%$, , , plus 2 tabletten (=125 mgr.) saccharine op 1 gram van

het mengsel S. G. + meel.

Van de beide soorten blad werd gelijkelijk zeer weinig gegeten.

$\mathrm{Na} 24$ uur werden de bepoederde bladeren weggenomen en onbehandelde er voor in de plaats gegeven; van deze werd door de proefdieren gretig gegeten; zij hadden echter van de eerste bladeren reeds zooveel gif binnen gekregen, dat na nogmaals 24 uur 3 , en na 72 uur in het geheel 4 van de 6 rupsen gestorven waren.

Ook loodarsenaat kon door saccharine niet aantrekkelijker gemaakt worden:

Proef 7 . 6 halfwassen rupsen bij tabak met:

$\mathrm{n}^{0}$. 1. loodarsenaat, $10 \%$ in cassave-meel,

$\mathrm{n}^{0}$. 2. $\quad, \quad 10 \%$ in meel +500 m.gr. saccharine op 50 gram van het mengsel

hadden voor geen van beide nummers eenige voorkeur.

Natrium-chloride - daargelaten dat het in de Delische tabakscultuur niet gebruikt zou kunnen worden, aangezien het een zeer slechten invloed heeft op de brandbaarheid van de tabak werkt afstootend.

Proef 8. 10 kleine en halfwassen rupsen bij tabak met

$\mathrm{n}^{\circ}$. 1. niets,

$\mathrm{n}^{\circ}$. 2. bevochtigd met een $10 \%$-ige zout-oplossing,

verkozen $\mathrm{n}^{\circ} .1$ boven $\mathrm{n}^{\circ} .2$.

Resultaat is, dat er onder de onderzochte stoffen geen gevonden werd, die op Prodenia-rupsen een sterke aantrekkingskracht bleek uit te oefenen.

Afstootend werkten, naast het S.G. en het loodarsenaat, tannine, en in mindere mate natrium-chloride.

In een lange derde serie proeven zijn voorts een groot aantal stoffen zoowel van organischen als van anorganischen aard op hun werking op de Prodenia-rupsen onderzocht; zij werden gekozen deels omdat zij als giftstoffen bekend staan, deels omdat zij scherpe, bijtende, bittere, verdoovende eigenschappen bezitten door de erin aanwezige alcaloiden, bitterstoffen, eiwitten, glucosiden, looistoffen, enz.

De nu volgende, alfabetisch gerangschikte lijst somt die stoffen op, welke de proefdieren noch afstootten noch eenigen merkbaren. invloed op hen hadden; de daarmede bepoederde of bevochtigde reepen tabaksblad werden even zoo goed verorberd als de onbehandelde, zonder de rupsen ziek te maken of te dooden.

Abrus precatorius, gemalen luchtdroge zaden. acetas cupricus, $10 \%$ in meel. aconitine, $1 \%$ in meel. 
agaricine, $10 \%$ in meel.

agaricus albus.

amygdaline, $10 \%$ in meel:

asa foetida, $10 \%$.

brucin, $10 \%$ in meel.

chloras baryticus, $20 \%$ in meel.

chromas stronticus, $10 \%$ in meel.

Chydenanthus excelsus, zaadkernen, zoowel fijngemalen als koude en warme waterige aftreksels.

cocculi indici, $10 \mathrm{gr}$. uitgetrokken in $500 \mathrm{cM}$. water, zoowel warm als koud.

coffeine, $10 \%$ in meel.

cortex mezerei, $10 \mathrm{gr}$. in $500 \mathrm{cM}$. water, koud en warm.

cortex quillajae, $10 \mathrm{gr}$. in $500 \mathrm{cM}$. water, koud en warm.

cortex rhamni frangulae, $10 \mathrm{gr}$. in $500 \mathrm{cM}$. water, koud en warm.

cortex rhamni purshianae.

cyanetum zincico-ferrosum, $10 \%$ in meel.

cyanetum zincicum, $10 \%$ in meel.

euphorbium.

extractum absynthii, $10 \%$ in water.

"aconiti, " , "

” belladonnae, , ",

" colocynthidis. " " ,

" digitalis, " " "

"hellebori, " " "

" hyoscyami, " " ,

" scillae, ", ",

" secale-cornuti, , " "

" stramonii, . , , "

"strychni, " " "

" thebi, ", "

fluoretum calcicum, $20 \%$ in meel.

folia belladonnae,

" coca.

, digitalis.

" hyoscyami.

" stramonii.

fructus anisi.

, colocynthidis.

hydrochloras chinini,

" cinchonini

": cocaini,

hydrargyrum sulfuratum

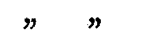

",

insectenpoeder, $20 \%$ in meel.

Isotoma, droog blad, in poeder en aftreksel, 1, 2 en $10 \%$.

kerriepoeder, $20 \%$. in meel.

lactucarium, $10 \%$ in meel.

piper album, $10 \%$ in meel.

radix gentianale.

" rhei.

rhizoma podophylli. .

saponine, $10 \%$ in meel.

secale cornutum pulvis, 100 en $10 \%$ in meel. 
semen physostigmatis, $100 \%$.

"strychni, 100 en $20 \%$ in meel.

smaltum, $20 \%$ in meel.

sulfas baryticus.

” chinini; $10 \%$ in meel.

thiosinamin, $1 \%$ in meel.

tubera aconiti, 100 en $10 \%$ in meel.

In tegenstelling met de bovenstaande oefenden de hierna te noemen stoffen wel een min of meer afstootende werking uit, en op kleine en halfwassen rupsen soms zelfs een doodelijke; groote rupsen evenwel gingen niet erdoor te gronde.

Niet afdoende werkten:

chromas zincicus, $10 \%$ in meel. Kleine rupsen gestorven.

creoline, poeder, $20 \%$ in meel. Enkele kleine rupsen dood.

cyanetum cuprosum, $5 \%$ in meel. Weinig gegeten, maar rupsen niet dood.

cyanetum hydrargyricum, $10 \%$ in meel. Weinig gegeten; enkele rupsen dood.

Derris elliptica (toeba); wortel fijn gesneden en met water uitgetrokken.

10 gr. op 100 c.c. heet water: van 5 halfwassen rupsen 2 dood, 3 levend.

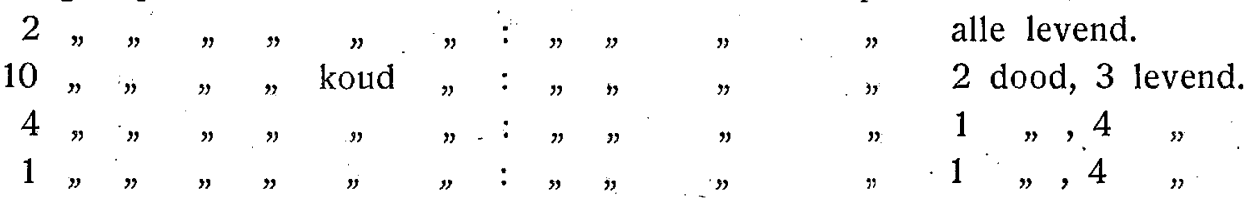

De uitwerking van dit dikwijls als insecticide genoemde vischvergift is derhalve niet bijzonder groot geweest, de ermede behandelde bladeren werden bovendien weinig aangevreten.

fluoretum natricum, $20 \%$ in meel. Weinig gegeten; enkele rupsen dood.

gutti, $100 \%$ en $10 \%$ in meel. Als boven.

menie, $20 \%$ in meel. Als boven.

Pachyrhizus angulatus, zaden, luchtdroog, gemalen, $20 \%$ in meel, $2 \%$ en $1 \%$ in warm en koud water.

Als boven.

quassin, $1 \%$ in meel. Werkt wel afstootend, maar rupsen sterven niet.

rhizoma hellebori, $100 \%$. De rupsen eten niet.

$" \quad " 100 \%$ in meel. De rupsen eten zeer weinig.

tuber colchici, $100 \%$. De rupsen eten niet.

$\eta \quad, \quad 10 \%$ in meel. De rupsen eten iets; enkele sterven.

Krachtiger werkten de volgende stoffen in de erachter vermelde concentraties; de meeste proefdieren, ook de groote, stierven, al hadden zij in alle gevallen ook maar heel weinig van de behandelde tabak opgenomen.

calomel, $20 \%$ in meel. Van de bladeren was heel weinig gegeten, maar de rupsen stierven.

cevadin, $10 \%$ en $2 \%$ in meel. Als boven.

cyanetum cuprosum, $10 \%$ in meel. Zeer weinig gegeten; vele dood.

iodetum hydrargyricum, $10 \%$ in meel. Zeer weinig gegeten; de meeste rupsen dood.

loodchromaat, $20 \%$ en $10 \%$ in meel. Geknabbeld; de meeste rupsen dood.

Pachyrhizus angulatus, zaden, luchtdroog, gemalen. Zeer weinig gegeten; de meeste rupsen dood.

thiosinamin, $10 \%$ in meel. Als boven.

veratrin, $10 \%$ in meel. Geknabbeld; alle dood.

Ten slotte zijn er enkele stoffen gevonden, die voor de rupsen blijkbaar niet onsmakelijk zijn, ja, welker aanwezigheid zij niet schijnen te bespeuren, daar de ermede behandelde bladeren grif opgegeten worden, en die toch fel doodelijk werken, t. w.: 
calomel, $5 \%$ in meel.

cevadine, $1 \%$ in meel.

nitras strychnini, $10 \%$ in meel.

Resumeerend kan gezegd worden, dat er zich bij de onderzochte stoffen geene bevonden, die op de rupsen van Prodenia litura een groote aantrekkingskracht uitoefenden, wel een aantal, die afstootend en meestal tegelijkertijd doodelijk werkten. Deze laatste zijn om verschillende redenen (prijs, bijzonder groote giftigheid ook voor den mensch) niet onmiddellijk in de praktijk bruikbaar, maar wellicht zal het de moeite loonen, met haar verdere proeven, op verschillende wijzen gevarieerd, te nemen. Ook tegen het Schweinfurter Groen en het loodarsenaat werden indertijd bezwaren geopperd; niettemin worden zij tegenwoordig in hoeveelheden van eenige tienduizenden K.G. per jaar gebruikt. 